\section{ANALYSIS OF FOODS}

\section{Food Ana'ysis}

Typical Methods and the Interpretation of Results. By Prof. A. G. Woodman. (International Chemical Series.) Fourth edition. Pp. xii +607 . (New York and London: MeGraw.Hill Book Co., Inc., 1941.) $28 s$.

$\mathrm{T}$ HIS is the fourth edition of a work originally published in 1915, and the declared intention of the author was then, and still remains, to provide a guide to students of analytical chemistry as applied to foodstuffs. A casual inspection of the contents at first suggested that there were some surprising omissions, but such criticism is promptly disarmed by the author who explains that his method was to select certain typical foods only, and to treat them at considerable length, so as to present the student with examples of the technique of food analysis rather than to cater for the requirements of the practising chemist.

While these intentions have been very ably carried out, it nevertheless seems to the reviewer that some of the material could usefully have been treated less generously, so that common foods such as cheese or dried milk might have received at least a mention; and that in six hundred pages devoted to food analysis, even if only for students, the word 'vitamin' deserves a place.

The first three chapters deal respectively with general methods of examination both physical and chemical, food microscopy, and colours and preservatives; here, as indeed throughout the book, the theoretical considerations involved in the various methods described receive adequate and capable treatment. One might query the statement con. cerning the presence of sulphurous acid and sulphites in foodstuffs that "there is no simple reliable qualitative test".

The section devoted to milk is fairly complete and up to date; the names of Gerber and WernerSchmidt do not occur and one notices that the average fat content in the United States is apparently higher than in Great Britain $(4 \cdot 0$ as compared with $3 \cdot 7$ ).

The general discussion of the examination of edible fats and oils, as well as that of the selected examples, namely olive oil and butter, is excellently written; it was noted that no mention is made of peroxide value. As with each of the typical foods dealt with throughout the book, the important question of the interpretation of results is carefully considered; this subject is often badly neglected, as more than one examination candidate has found to his cost.

Following a comprehensive description of the methods in common use for the analysis of carbohydrate foods, with particular attention being devoted to sugars and certain chosen foods, the remainder of the book deais with spices, cider vinegar, flavouring extracts and alcoholic beverages, more than one sixth of the whole book being allotted to the last-mentioned subject.

Woodman is very 'readable', and his book, in which no typographical errors were detected, is much less obviously American than most scientific publications from across the Atlantic. While many of the diagrams and tables have a familiar appearance, their source is invariably indicated with due acknow. ledgment. Very full references are given in foot. notes and at the end of each chapter a list of books is given to which the attention of the student is directed for further study. A. F. LERRIGo.

\section{MATHEMATICAL REQUIREMENTS FOR STATISTICS}

Statistical Procedures and their Mathematical Bases

By Dr. Charles C. Peters and Prof. Walter R. van Voorhis. Pp. xiii+516. (New York and London: MeGraw-Hill Book Co., Ine., 1940.) 31s. 6d.

THIS book is the outcome of a serious attempt to derive accepted statistical methods and formulæ from elementary mathematics. It opens with a chapter called "A Little Calculus"; and it may be presumed that the mathematical proficiency of the reader marches pari passu with his reading of the book, for the later chapters are on such subjects as partial and multiple correlation, the normal curve, non-linear correlation, analysis of variance, curve fitting and so on.

The point of view of the authors is easily comprehensible, and merits sympathy. On one hand we have books such as R. A. Fisher's "Statistical Methods for Research Workers", which promulgate formulæ and procedure by the voice of authority, without descending to proofs ; on the other we have few text-books, but a profusion of memoirs, not only abstrusely mathematical, but often controversial. A student or researcher, initially of slender mathematical equipment and desirous of applying statistical methods to some problem of research, may well foel at a loss. This book is intended to help him, and without doubt, by the time he has read its almost five hundred pages (the last thirty are devoted to useful tables) he will know a great deal about questions of distribution, correlation, regression, the $\chi^{2}$-test and the rest. Will he be able to digest his knowledge and discriminate?

While fully sympathetic, one may feel dubious about the efficacy, and even the desirability, of such an approach. Envisage a continuous variate; the compound probability of even two individuals involves a double integral, and $n$-fold integrals with very large $n$ are the merest commonplace. Consider again the question of partial correlation; the abstract underlying ideas are those of linear transformations and positive definite quadratic forms. Indeed not only the infinitesimal calculus, but also algebra, both matrix and combinatory, and some notion of the geometry of hyperspace are prerequisite to the study of statistics. It is better that these fundamental preliminaries should be mastered as if for their own sake. Then, when the time comes for application to mathematical statistics, one will have a background not merely for understanding and applying, but also for doubting and reserving an opinion; for high authority does not yet speak with a single voice.

A truly elementary and comprehensive book of this kind would have had to be at least twice as long again. For example, the normal function is deduced from the exceedingly special case, the symmetrical binomial; while the $\chi^{2}$-distribution and many other results are only incompletely established, the reader being referred to more advanced treatments. 